\title{
Process not Product: Arc, Hull's Architecture Centre
}

\author{
Chris Hay \\ School of Architecture, University of Lincoln, Brayford Pool, Lincoln, LN6 7TS, United Kingdom \\ *Corresponding Author: chay@lincoln.ac.uk
}

Copyright (C) 2013 Horizon Research Publishing All rights reserved.

\begin{abstract}
This paper discusses the Arc project in Hull. It takes the form of a case study of a building conceived from the outset as having no fixed final form or indeed permanent location. The first iteration of the building, designed by Niall Mclaughlin Architects, was completed in 2006 and houses the events space and offices for Arc, the Architecture Centre for Hull and the Humber Region. The project grew out of an initiative formed by collaboration between academics from the two local Universities, plus Community and Business representatives. The intention was that the organization would act as a catalyst for change, and raise architectural aspirations underpinned by an ethos that local people were experts in their own lives. Arc did this through a series of interlinked programmes including Design Review, and the Learning and Public Realm programmes. In addition the building hosted exhibitions, debates and workshops. This is a timely moment to revisit this project as the particular set of circumstances that enabled the building to be realized have already passed into history. Arc both as a building and as organization can now be seen as representative of a particular political and cultural moment in the UK, one that is now firmly over.
\end{abstract}

Keywords Architecture Centres, Relocatable Buildings, Regionalism, Participatory Design

\section{Introduction}

This paper explores aspects of the design and subsequent realization of Arc, the building that housed Hull's Architecture Centre. The term Arc in this context is an acronym and stands for Architecture, Regeneration and Community. It is used here both to describe the Architecture Centre as an organization and to describe the building that housed the organizations activities. It is the building rather than the organization that is the main focus of this paper. The building was realized in 2006 on a site in the city of Hull which is in the East Riding of Yorkshire, England, on the north bank of the Humber estuary some 24 miles $(40 \mathrm{~km})$ from the North Sea. The building, commissioned by the charity which ran the centre, of which the current author was a founding member and client sponsor for the project, is relocatable and came into being because the availability of capital funding created the opportunity for the then new organization to provide both a home for its activities and to express its aspirations in physical form.

The opportunity to build was an exciting one as it enabled Arc to reflect on its approach to architecture and to people and place. It was in effect an opportunity for Arc to directly address issues that its founding members believed to be important in any new building project. At the heart of these were two overriding concerns. These were, firstly how to involve local people in design-decision making in meaningful and productive ways and secondly how to make a modern architecture that resonated with the city that produced it and the context in which it would sit. The building project thus became a test bed for these concerns in practice.

Arc addressed the first of these concerns by using a participatory methodology, discussed later, to ensure the efficacy of the process and, because the project was ultimately concerned with the relationship between bodies and places I suggest that a phenomenological perspective can usefully be brought to bear when analyzing the resultant building.

Before examining the building project itself it is worth noting that the ideas which informed its brief came out of a particular set of circumstances, both national and local, which together resulted in the commission being realized in the way that it was. Nationally, CABE, the Commission for Architecture and the Built Environment, invited bids from interested local groups to research the viability of establishing an Architecture Centre in their local area. In response to this the founding members of Arc proposed an organization which would work closely with local communities of interest, be they schools, businesses, community groups, local councils, and the public in general in order to raise interest in the built environment generally and to foster, wherever possible, an appetite for quality in new design proposals of any kind. In parallel with the development of Arc as an organization came the chance to build and Arc duly became the first, and so far only UK Architecture Centre to commission a building for its own use. 


\section{Context}

ARC was founded in 2003 and was one of twenty-two, at the peak, independent Architecture Centres that existed throughout the United Kingdom. The organization grew out of a local initiative whose members came from education, the University of Humberside (as was), in the form of the School of Architecture, now part of the University of Lincoln and The University of Hull working together with the local Community Regeneration Company, Hull Doc, the Local Authority itself and Cityvision, the then Regeneration Agency. The organization's purpose was to raise the quality of the city and sub-region's urban design, architecture and public space and it did his through developing and delivering programmes and services designed to encourage people of all ages, and from all walks of life, to take an active interest in the architecture and built environment which surrounds them. [1]

\subsection{Hullness}

Each of the United Kingdoms Architecture Centres is different, they all respond in varying ways to the locations in which they work and one of the underlying ideas behind Arc was an attitude to people and to place. We took the view that Arc should engage with local people, and to engage with them where they live and to recognize that people are 'experts in their own lives'.[2]. We also believed that if any architectural propositions supported by Arc were to have lasting value or meaning they had to recognize that Hull was a particular place and that it is one that, despite its checkered history, or indeed because of it, possesses a strong sense of character and the particular. Having said that we were aware, as David Leather barrow has pointed out, that history cannot be simply appropriated. He observes that " there are two ways of being mistaken about history: one is to see it as something outside of the present, what was and is no longer, and the other is to view it as something which constitutes the present, what we are now within. The truth of the matter is neither so far off nor so near. Similarly the present is neither so empty nor so full.' [3]. We were thus interested in questioning how a building designed today could or should relate to its place, to its physical setting, but also, and most importantly how it could be seen to be relevant to the people who lived there.

The structure of places, is not fixed however, for as Norberg- Schultz has pointed out, they change and adapt, but places or 'Stabilitas Loci ' do need, according to him, 'to preserve their identity over a period of time' [4] in order that they may be recognized. This interpretation of place inevitability implies a degree of stability and continuity, which were qualities that we knew that any building we commissioned could not in practice possibly have. It would inevitably be ephemeral and transient. The nature of the commission meant that the project would, like all buildings, have to contend with the seasonal circumstances of climate and the diurnal cycles of light and dark, but it also precluded the deployment of any of the more durable aspects of local building culture, such as brick or stone, which might normally be expected to enable a building to be recognized as being a part of the city that had commissioned it. The question that Arc had posed, firstly for itself and subsequently for its architect, was how should a temporary structure contribute to an existing environmental or architectural character and to this particular city and its many and diverse communities, when the very nature of the commission suggested that certain avenues were closed? The answer to these questions lay in McLaughlin's insight that the context for the project was not primarily a material one, important as that would be, but that it was societal, and if we started by engaging with the cities manufacturing base and listening to its people and their stories, we would find that an architecture capable of resonating with them would emerge out of these conversations, and if certain material or constructional strategies were precluded then this would enable the project to open itself instead to others equally potent in their relationship to local circumstances.

\subsection{The Commission}

The commission arose from the opportunity to house Arc's progammes by providing a flexible learning and exhibition space supported by offices and ancillary spaces for staff and visitors. We had access to funds, which were themselves subject to time constraints, and we found that although we could build we did not have the resources to acquire and do so on a permanent site, and this meant that time would play a decisive role in both what and where as well as when something could be achieved. The resultant project had to negotiate the pragmatic and to exploit opportunities as they arose. We were fortunate that our inability to commission a permanent building fitted with our intention to take Arc to where the issues were and not rely always on the issues finding Arc. We were thus contemplating a mobile or moveable structure, which would, like a fair or a circus, move from site to site within the city as funds, and opportunities presented themselves. Thus the project from the start embodied change and processes of making, unmaking and remaking.

We had of course to start somewhere and, in partnership with Hull City Council, we examined underused or vacant land which the city owned and in due course Arc entered into a lease with them, granted on a peppercorn rent, for the use of a city centre site on the northern edge of the fruit market area adjacent to the A63 corridor which connects the city to its port but which also severs its connection with its waterfront and the estuary itself. The lease was granted on a temporary base and was and is subject to renewal or otherwise depending on the likely hood of redevelopment.

\section{A Participatory Approach}

The appointment of an architect was done by means of a competitive interview. Arc invited a number of practices to 
propose an approach to the commission rather than possible design solutions to the brief. Niall McLaughlin was subsequently appointed partly on the basis of the approach that he outlined, but also because of his previous successful experience with working with school children on the design of his bandstand at the De La Warr Pavilion realized at Bexhill-on-Sea in southern England and completed in 2002.

The design process began with a series of workshops that were arranged to be as inclusive as possible and to which people were invited who represented as many of Hull's diverse communities as we could engage with. The methodology adopted at these sessions was based on Participatory Appraisal (PA). This is a process that values local people as experts on their own lives and places, and which combines community research, learning and collective action. PA was first employed by British and Kenyan practitioners in rural communities in Africa [5] and two of Arc's board members, Susie Hay and Gill Hughes, who are trained PA practitioners, brought their expertise to bear in designing these sessions. According to Susie Hay, PA 'is not a scientific research approach, but looks rather to collect highly qualitative information relating to participants experiences, and perceptions of reality, to acknowledge issues and to plan for change' [6]. Sybille Manneschmidt has also argued that PA differs from more traditional extractive research methodologies in that group members are key actors. Their knowledge and experience is a basis for achieving understanding.' She goes on to say that 'as group members present and analyze their "own" data and define preferences and priorities towards a more developmental process for their community, information is not extracted from but rather is owned by the community'[7]. It was this sense of collective ownership of emerging issues that PA produced that was especially valuable to the design team and to local people who participated. Their success can be evidenced by citing the Rev Mike Hills, a local community leader who said 'this community has been consulted to death, we are asked out views on almost everything, and mostly nothing happens. Here, for the first time we can see how the communities concerns have been reflected in an actual proposal'. [8] Thus the design emerged from a process of parallel learning where as I have suggested earlier 'the architect and community representatives came together to exchange expertise (in order to) establish a sense of ownership by the community in the design.'[9] Of all the narratives that emerged from these sessions the loss of the cities connection with the sea because of the decline of its fishing industry and the subsequent erasure or denial of these memories through a desire in the recent past to embrace a different future emerged as a touch stone for the project.

\subsection{The Cup and the Saucer}

We began the project with the knowledge that the building would move and of course most buildings don't move from the site of their construction. They are built, then inhabited, altered, repaired, or otherwise and ultimately demolished, all in the same place. The land or the site on which they stand is, as Stewart Brand [10] has pointed out, the most permanent thing about them, and everything else is, even in the most lasting of structures, as Ed Hollis [11] has eloquently demonstrated in his exploration of the histories of the Parthenon, is susceptible to change in one way or another. McLaughlin's view of change was that it needed to be embraced, and his thinking here is close to Frank Duffy's [12] in his analysis of how time affects the various components and systems of commercial office buildings in different ways. Duffy has shown that the how, when and why of any change does not uniformly effect all aspects of a buildings fabric in the same way. Some aspects of buildings change far more rapidly than others as factors such as the difficulty or ease of altering something, the durability of materials and components, their accessibility, or otherwise, and the availability of resources, both material and economic all play their part in preserving, or otherwise, the various systems or layers which make up their being. Rather than seeing buildings as permanent, or "hardened into a temporal categories of order, and thought to be eternal and true" [13], an example of which one can see in Corbusier's white villas of the 1920's, which seem to deny the very existence of time and exist only, as it were, in a permanent present, unable, like Dorian Grey, to age. The Arc project actively embraces change and uncertainly and the creative possibilities offered by them.

McLaughlin's first ideas contained a powerful metaphor to describe the relationship between the building and its site, which he characterized as being like that of a cup and a saucer. The site here stands in for the saucer and the building for the cup. Mclaughlin was alluding to the way a cup is housed by its saucer and that when the cup is removed the memory of its presence is still seen in the depression left behind. Thus when the building is first moved an impression of its placement in the ground is left and a memory of its presence remains. This sensibility has phenomenological roots I would argue. Maclaughlin conjures an image of a vessel, a bounded container, a place for human interaction, located both in and on a particular place. This is an archetypal image for as Karl Bloomer and Charles Moore remind us 'the landscape of the inner world of landmarks, coordinates, hierarchies, and especially boundaries serves, we believe, as the only starting point for the organization of space around us, which more than being perceived, is inhabited by us'. [14]

\subsection{Earthwork and Framework}

Mclaughlin's instinct was to incorporate the very ground itself into the building. He proposed a lean-to structure, rectangular in plan, whose roof would rest on a long wall, a gabion filled with material directly taken from the site. The resultant interior volume would house all the necessary accommodation with the sloping roof forming the main 
elevation to the east and the wall the rear elevation to the west. This material and construction strategy takes us close to Gottfried Semper's understanding of primitive construction, which he developed after seeing a Caribbean Hut at the Great Exhibition of 1851. Semper proposed that the primordial dwelling was divided into four basic elements: the earthwork, the hearth, the framework/roof and the enclosing membrane. [15] Kenneth Frampton, refines this idea and suggests that, according to Semper, the buildings crafts can be understood as being essentially two fundamental procedures, namely 'the tectonics of the frame combined with the sterotomics of the earthwork'. [16]. Thus we can see Mclaughlin seeking to create an enclosure which relates to what is below - the earth, on the one hand and what is above - the sky on the other. Edward Casey suggests that these are the 'separate protoregions of ordinary perception; they divide up the perceptual landscape from the beginning' [17] and I suggest that Mclaughlin here is referring, through his spatial and constructional strategy to shared perceptual understandings of the world and how buildings can be formed within it. In the event the earth wall did not survive into the final design proposal but its echoes can be seen in the $\mathrm{red} /$ brown coloration on the service pods in the computer images of the building (see fig 1.)

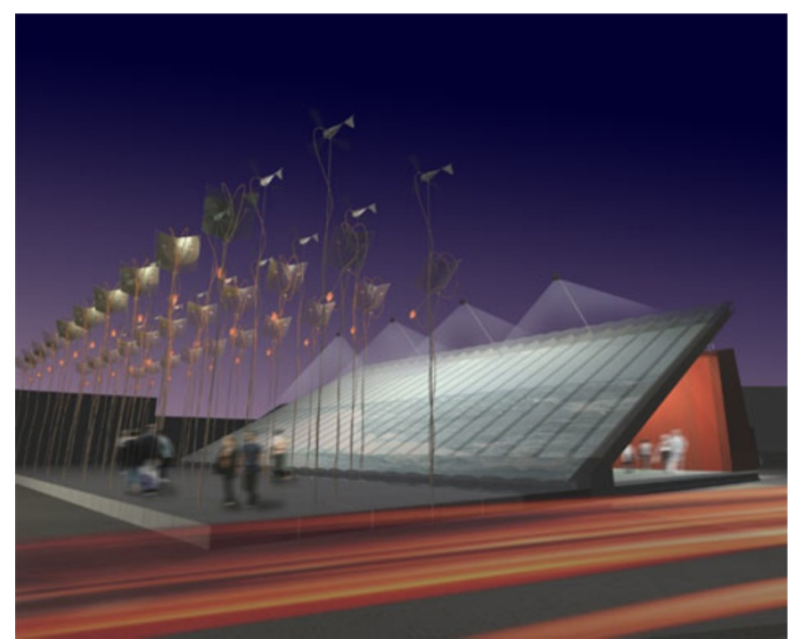

Figure 1. Night view in Context

\subsection{The Building and Time}

Mclaughlin proposed that Arc was not commissioning a building but a 20 -year long narrative which, like all good stories, starts out somewhere, and after a number to twists and turns ends somewhere else entirely. He suggested a process of making, unmaking, moving and remaking where each iteration of the building becomes an opportunity to revisit the design and its components in order to see which are still relevant, appropriate or indeed obsolete and whither they need to be replaced or reconfigured in response to the possibilities presented by their new location. I would suggest that Arc as an idea can be best understood as a phenomenon which is time based, like film, where at any point in its existence one is experiencing it like a still taken from a stream of events, a moment in the story but not the whole picture itself. The question is not what Arc is but rather when it is. Arc it is a process not a product, and is in a continuous state of becoming.

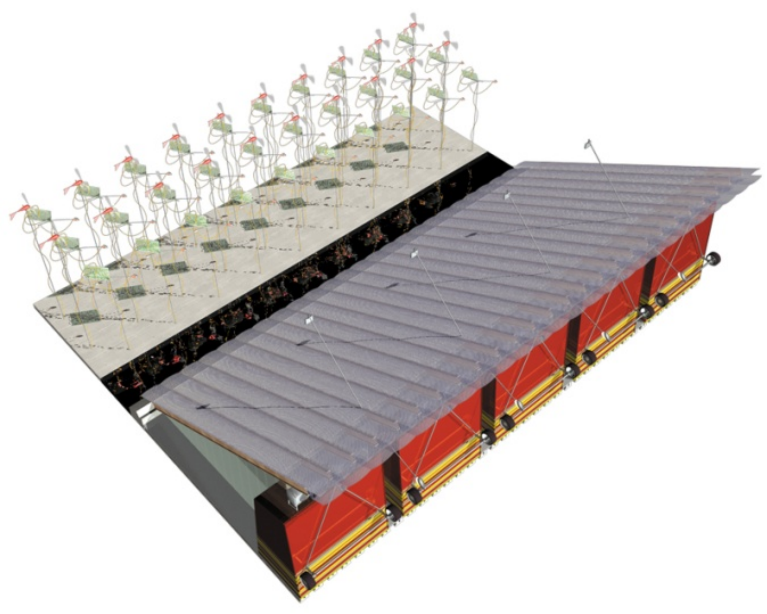

Figure 2. Axonometric from the rear

Before discussing the project as built it is pertinent to reflect on the relationship between the project as an idea and the project as a building. Like most architects today McLaughlin's office makes drawings, models and written specifications that are all, in some form or another, representations of the design. They in effect describe it in an ideal state - fixed as it were in the virtual space of the computer and thus standing outside of the processes to which the building they describe will itself be subjected. In contrast to this perfect state, however, the world that the building inhabits is not ideal it is itself fluid and uncertain. Thus for reasons such as the finite sums of money available, the time limits in which the various funding streams had either to be spent or lost, unexpected costs imposed on the project and normal contractual difficulties that affect any building project, the building as first realized does not conform in several respects to the design as projected in the architects drawings.

For example the Highways Agency were concerned that the buildings unusual shape would cause possible traffic accidents as drivers would be distracted and lose concentration as they approached it from the east. To counter this Arc had to commission, at some cost, an independent analysis of any likely risk and, by citing structures such as the London Eye or the Angel of the North and by demonstrating that they had no detrimental effect on passing traffic we were able to convince the Agency to allow the project to proceed. 


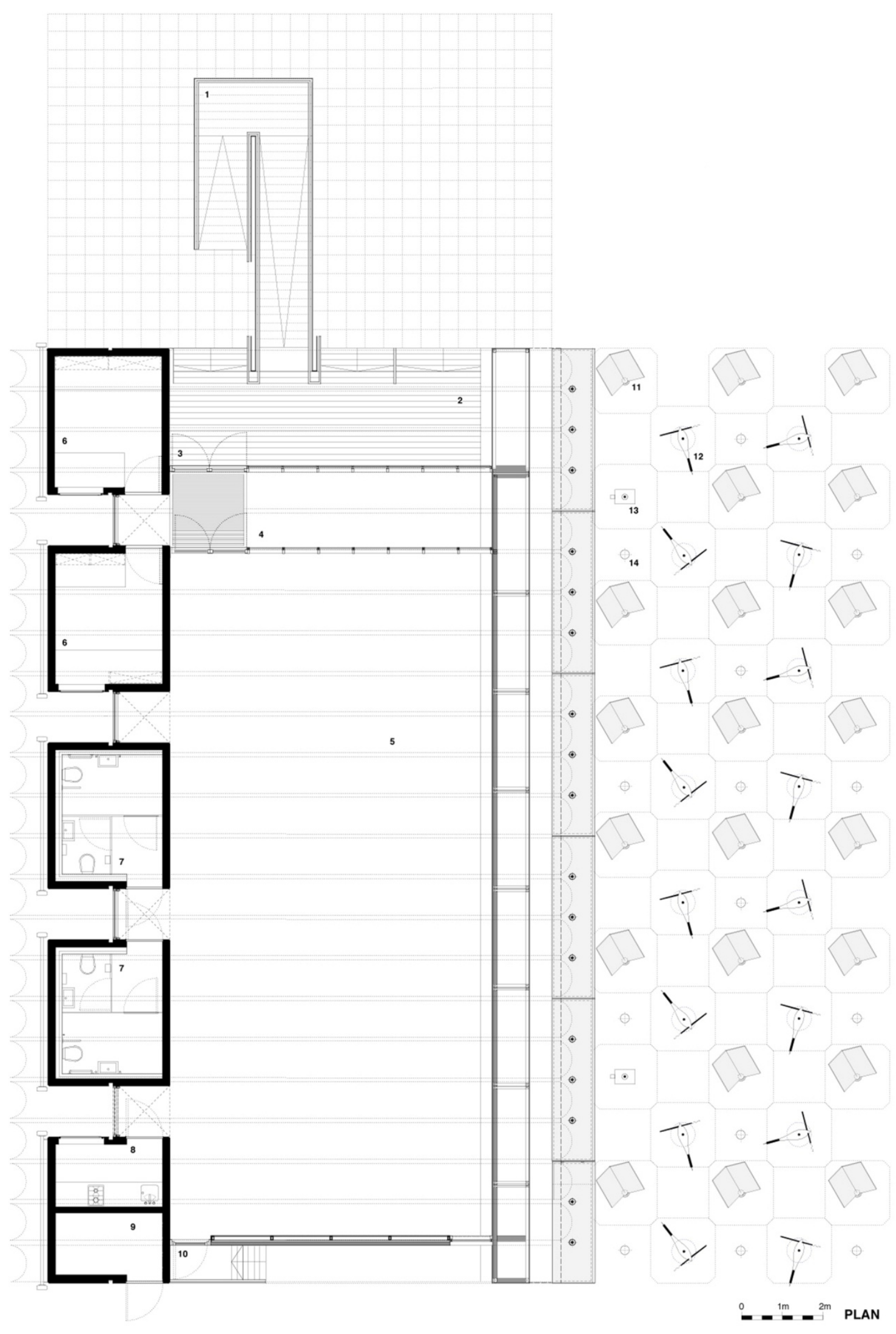

Figure 3. Plan 


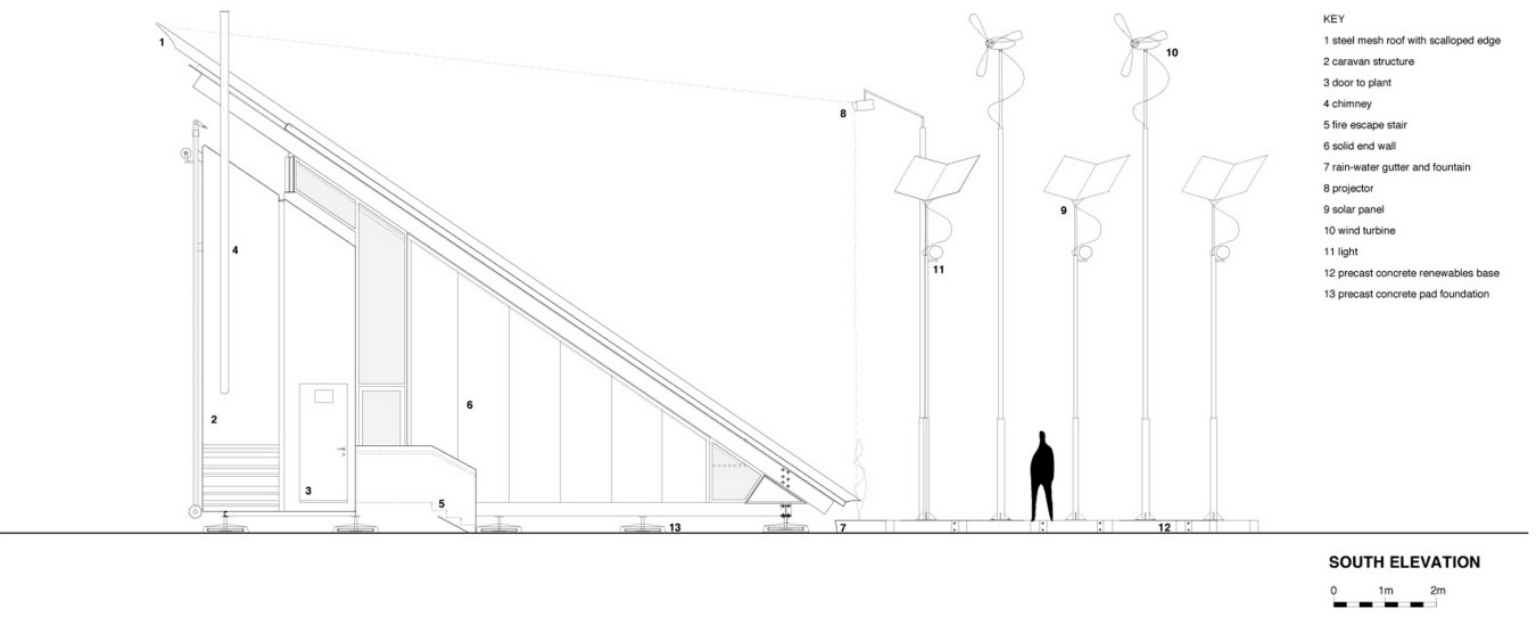

Figure 4. Elevation

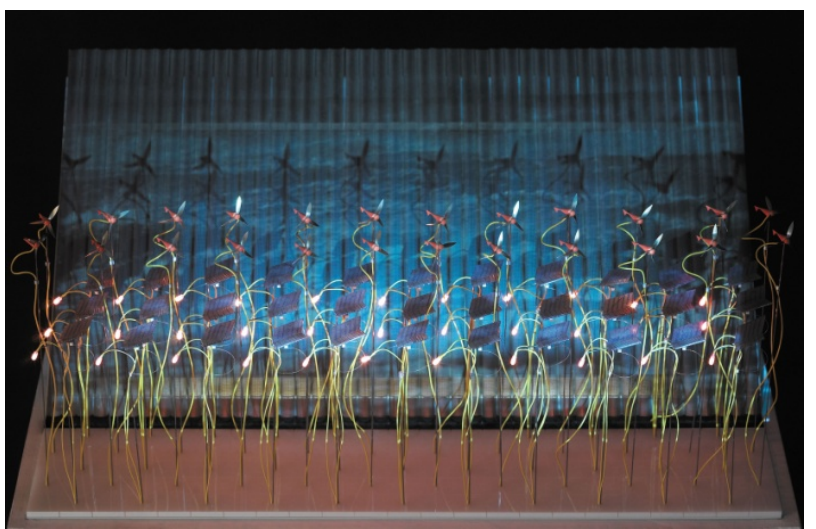

Figure 5. Model photograph of projection

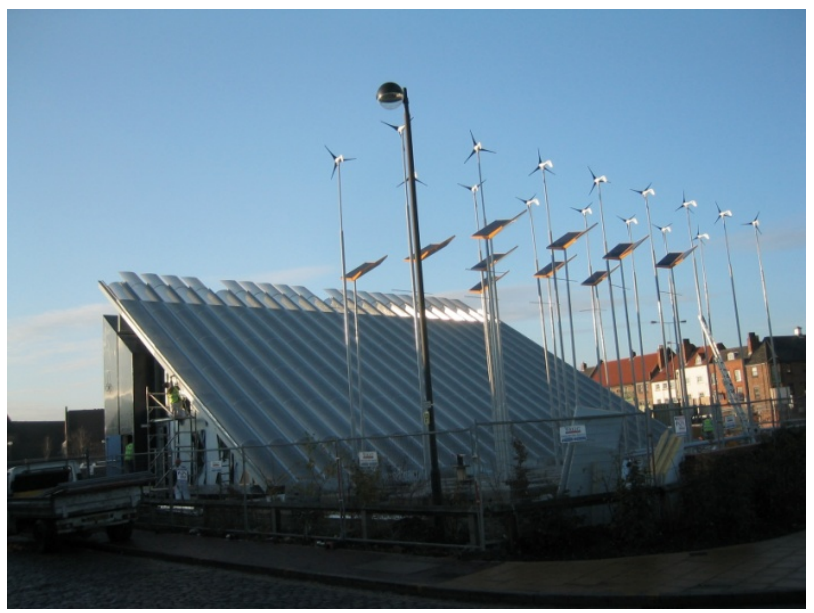

Figure 6. East elevation

Thus aspects of the design were either amended or omitted altogether. The external assess ramp was redesigned and simplified, and the internal scalloped mesh ceiling panels and mobile storage wall were omitted altogether. These alterations in themselves did not seriously compromise the quality of the completed building as can be evidenced by the design awards it subsequently won and it can be argued that the loss of the ceiling mesh subsequently enabled an inventive appropriation of the ceiling plane as part of an exhibition on Hull's stories, see figure 7, which would not have been otherwise possible.

This disconnection between project and building illustrates that it is only in the world of the ideal, where as Edward Hollis has suggested, [10] things are perfect and therefore fixed; anywhere else they will be dynamic unstable.

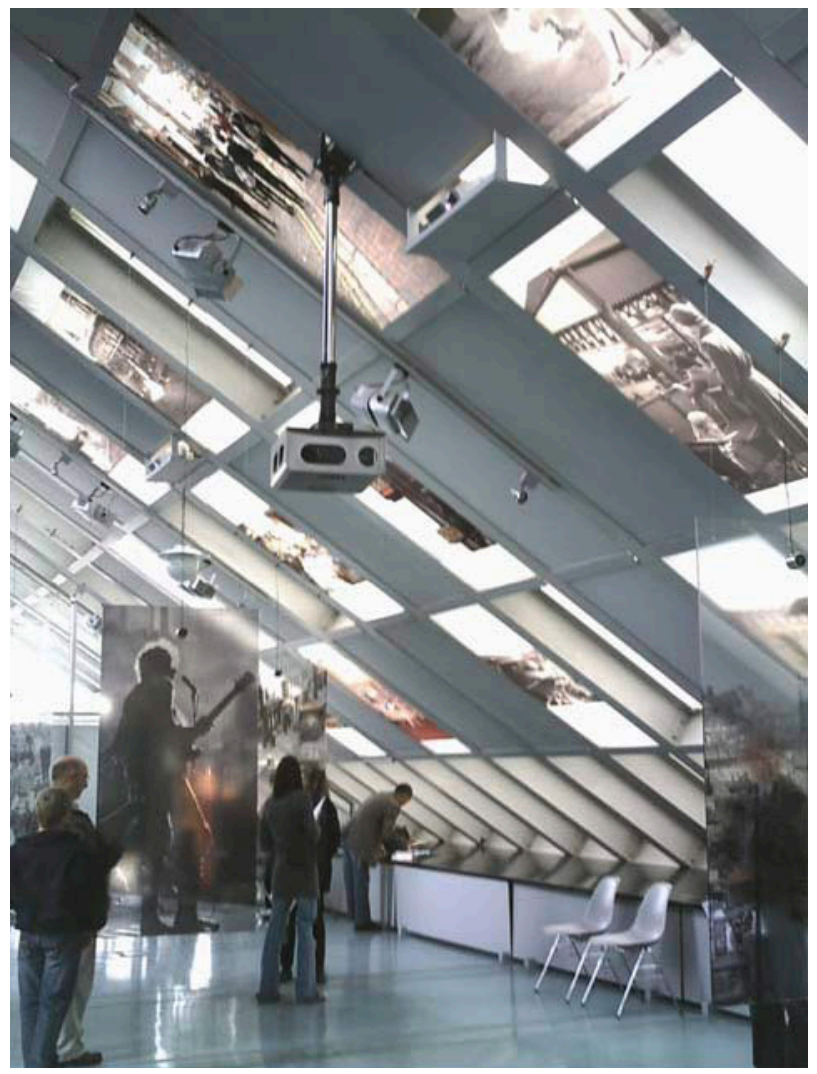

Figure 7. Interior

\subsection{The Project as Built}

The brief asked for the provision of an adaptable space, 
one that could be used for exhibitions, meetings, workshops and events of various kinds and the resultant design accommodates this in a simple and straightforward manner. The interior is formed by an inclined plane that leans against a line of apparently upended blue caravans, or service pods, five in number. This creates a sheltered space akin to a den that a child might make by leaning some branches against a garden wall. Sitting directly in front of the sloping roof, which forms the main elevation of the building, is an array of solar panels and wind turbines, whose heads, like mechanical flowers are lifted and orientated towards wind and sun to make what McLaughlin refers to as a mechanical garden.

The resultant building is, I would argue syncretic in nature, and brings together a way of thinking about buildings which one can see in aspects of the work of Jean Prouve, for example in his exhibition pavilion for the Butagaz company at Nancy of 1953, or in the more recent work by Renzo Piano, as in his mobile exhibition building for IBM of 1982-84, where the building is conceived as a mechanism or machine. Located within a particular seam of modernist architectural thinking this 'high tech' way of approaching construction usually aspires to be as Kenneth Frampton points out, nothing more than 'elegant engineering'[18] with 'the corresponding victory of universal civilization over local culture'. [19] Here this generalizing tendency is countered with an interest in the specific akin to the practice of artists such as Susan Hiller, who according to Anne Gallagher ' combines objects and images from a variety of sources, to provide the viewer with an array of tantalizing fragments of cultural memory from which to form their own associations and meanings' [20].

The building is as much a product of local stormemories and about the land and the weather as it is concerned with manufacture and production. It is something which is capable of transformation and relocation yet deeply concerned with place and the particular characterizes of the local.

The sloping roof is orientated to the east and faces the incoming traffic arriving into the city over the river Hull. The plan, as yet unrealized, and now wholly dependent on the buildings new owners, was to use the roof like a roadside billboard and project images of the sea onto its rippled metal surfaces. McLaughlin's thinking, drawn form the earlier participatory workshops, was that at night the building would "dream about the sea and Hull's seafaring past "[21]

The building was designed to be dismantled, moved, then re-erected and its larger components are sized in accordance with vehicular dimensions to facilitate this process. The floor structure therefore comprises a series of steel cassettes, of standard road haulage width, filled with ballast, and subsequently bolted together. The outer roof surface is formed by a series of curved mesh aluminum panels which can, along with the translucent insulation panels which sit under them be easily lifted off and once this is done the steel beams which form the structure of the roof itself can themselves be dismantled. The 'caravans' are self-contained and can be moved short distances on their wheels and over longer distances on the back of a low loader. The building has no foundations as such and because of its low lying site and the possibility of flooding, sits on adjustable legs like a large piece of furniture, which lift it clear of the ground.

The building responds to its location through its orientation and the ways its surfaces work. The raised ground floor floats above the site because of flooding risk. It captures the wind and the sun through its array and it is naturally ventilated and cooled in the summer through exploiting its section and the cooling action of air passing over water. Its wood pellet boiler heats the floor in the winter and an even east light washes its interior through the inclined roof and a dramatic west light enters from between the caravan pods. The building also flexes, moves, and creaks in the wind and when the rain drums on its roof one feels in touch with the elements like being on a boat. From a phenomenological perspective the building is imbued with haptic and kinesthetic qualities. Additionally the building also responds to the larger context of the Humber through the thicket like nature of its energy gathering garden, and to the wider landscape of wetlands and reed beds that predate the cites foundation, and which still, in places, form the shifting edge of the estuary on which it stands.

Local industries also contributed to its form. Hull is a significant manufacturer of caravans and mobile homes and the design exploits this expertise and makes reference to this tradition, though in unsurprising ways. The five service pods, which contain offices, toilets, kitchen and plant are deliberately caravan like in their form but are used here as if upended. Their colour also makes reference to local memory and they are a deep blue because Reckitt's Blue pigment has been manufactured in the city since the early $19^{\text {th }}$ century. The perforated aluminum roof panels, which form the external tilted screen, were made locally by a company which started out by making metal fish boxes for the local fishing industry and these are shaped to add strength and to channel rainwater off the roof and are scalloped to meet the sky in a manner analogous to other public buildings in the city. The wind turbines \& solar array, which help define the building and give it presence, also take their place amongst the plethora of road signs and security cameras which are found around the site and, despite its uncompromising and surprising shape, allow it to become just another element in the everyday urban furniture of the city, a product of contemporary building technology, but also a product of Hull.

\section{Arc in Use}

Since the building opened Arc has made an important contribution to local and regional debates on design quality thorough engaging with people from all walks of life, from school children, the general public and built environment professionals alike in a variety of different settings and occasions. Arc has delivered an education programme which has worked with over 150 regional schools, it has mounted a 
variety of exhibitions, both in the building and off site on topics such as Drawings Boards and East meets West Exploring Hull's heritage and it has run an annual series of open lectures. It has worked with Hull City council to deliver the cites Public Arts Programme and has, through the mechanism of Design Review offered independent advice on over 80 proposed developments in the city and region. [22]

\subsection{After Arc}

This contribution to the cites recent cultural life and of the use of the building in its capacity as home to the centre's activities came to an end however on $15^{\text {th }}$ May 2013 with the closing of the building and of the charity that brought it into being. This event can be seen both as a loss to the City of Hull and to Humberside generally and as an example of the national retrenchment which has occurred since the election of the Conservative Liberal Democratic coalition government in 2012. Thus Arc, both as an organization and as built form can be said to represent a particular political and cultural moment in the United Kingdom where central government, working through regional development agencies, in this case Hull City Vision and Yorkshire Forward, had the capacity and the desire to support regional initiatives, such as Arc in their aims to engender local interest in, and to act as a catalysts for, positive change in the built environment. This is a period which can be said unfortunately, as being now firmly over.

Arc was born under what was called New Labour. It was supported by CABE, The Commission for Architecture \& the Built Environment, the local regeneration agency CityVision and then its successor Hull Forward and by Yorkshire Forward, the regional regeneration agency and it was able to tap into funding streams, Regional, National and European directed at supporting disadvantaged communities and encouraging inward investment.

We are now in different times of course, the recent recession halted Hull's regeneration in its tracks. On the one hand any pressure to move the building due to the site being required for redevelopment vanished which eased financial pressure on the organization as potential moving costs receded but on the other the policies of the new government simply increased the pressure as it abolished both Hull Forward and Yorkshire Forward and funding streams dried up. The infrastructure that enabled Arc to come into being and which supported its activities has simply vanished, or is in the case of $\mathrm{CABE}$, is much reduced.

Arc responded to changing circumstances as best it could, it lost staff and redirected its energies but in May 2013 the inevitable happened and the building was put up for action by the city council, who became by default owners of the building as Arc's board took the decision to wind up the charity and close the organization. This event, registered in the local media because a local landmark was closing, and more widely in the UK architectural media because of the innovative nature of the building, marks the end of this particular chapter of the buildings story, namely 10 years of work of Hulls Architecture Centre.

The building was bought by Terry Hodgkinson, a regional property developer, [23] and former chair of Yorkshire Forward, who has a keen interest in regeneration, and who has announced that he hopes to keep the building for public use and to move it in due course to another site in the city. In the short term the building is already in use as a venue for a leadership programme run by a local business. [24] and its future seems assured. It is, however, instructive to note, and a clear sign of changing times, that in order to ensure this future the buildings ownership has moved from public to private hands.

\section{Conclusion}

The aim of this paper has been to suggest that community involvement in the form of a qualitative participatory process can inform design and result in a building which, whilst clearly authored by its architect, and widely praised for its design quality [25] is, because of its surface and material qualities, open to a variety of interpretations and to resonate with the local environment and industrial context The resultant building, I would argue, and any qualities that it might have, come about precisely because both architect and community representatives were clear regarding their respective roles. The community participants were recognized as being expects in their own lives, as understood by participatory practice, and the architect as an expert in design. All parties exchanged views and, through mutual respect, learnt from one another.

This desire to involve local people in the design process was not an attempt to create a shopping list of desirable attributes, or to dictate matters of form or material. Rather the process recognized that, as contemporary hermeneutics suggests 'that meaning is always dependant on context and no one perspective should be privileged, because contexts are endless' [26] Thus Arc and its architect were in agreement that what we were seeking was not an architecture of modernist abstraction but rather one that was capable of multiple readings or interpretations. One were the buildings material surfaces and architectural expression would, despite their initial unfamiliarity, mediate between individual experience and the cites emerging collective identity.

Ideas of change, adaption and relocation were envisioned for the building from the start and it is somewhat paradoxical that the organization that commissioned it has not been itself able to demonstrate the same ability to survive in the face of change. Arc found that slowly but surely the funding environment that nourished its work has disappeared and, like an overspecialized organism whose food supply has gone the organization has not been able sustain itself in the hasher economic climate of recent times.

The paradox here is that a building designed to change and move has yet to do so and yet everything around it, the organization which commissioned it, the work that is does, the political and funding context which supports it and the 
regeneration context in which it operates have all themselves fundamentally changed and are in many cases unrecognizable in comparison to what they were when Arc began.

One can only note that change happens and it does so in unpredictable ways and whither we like it or not.

\section{REFERENCES}

[1] Online available from http://www.arc-online.co.uk/home

[2] Hay S, Online available from http://shortwork.org.uk

[3] Leatherbarrow D, The Roots of Architectural Invention, Cambridge, 1993

[4] C. Norberg-Schultz, in K. Nesbitt. ed. Theorizing a New Agenda for Architecture, Princeton, 1996

[5] R. Chambers, Participatory Rural Appraisal (PRA): Analysis of Experience, Elsevier Science Ltd, World Development , Vol 22, No9, 1253-1268, 1984

[6] Hay S, Online available from http://shortwork.org.uk

[7] S. Manneschmidt. Participatory Rural Appraisal Tools, Pincher Creek, 2001

[8] Hills, M, quoted at a workshop held at the Ferns Gallery, Hull, 2003

[9] C Hay, in N. Marchettini, C. Breddia, E Tiezzai, L Wadhawa, eds. Sustainable Cites 3. WIT press, Southhampton, 2004

[10] S. Brand, How Buildings Learn, Phoenix Illustrated, London, 1994

[11] E Hollis. The Secret Lives of Buildings, Portobello books,
London, 2009

[12] F. Duffy, in S. Brand, How Buildings Learn, Phoenix Illustrated, London, 1994

[13] D. Leatherbarrow. Uncommon Ground, MIT press, 2002

[14] K. Bloomer, C. Moore. Body, Memory and Architecture, Yale University press, CT and London, 1977

[15] K. Frampton. Studies in Tectonic Culture, MIT press, Cambridge MA, 1996

[16] Ibid.

[17] E. Casey, The Fate of Place, University of California press, London, 1998

[18] K Frampton. Modern Architecture: A Critical History. Thames \& Hudson, London, 2007

[19] K. Frampton. Labour, Work \& Architecture. Phaidon, London. 2002

[20] A. Gallagher. ed, Susan Hiller, Tate books, London, 2011

[21] N. Mclaughlin. Stage D report to HCEBE, 2003

[22] Online available from http://www.arc-online.co.uk/home

[23] Hodgkinson T, Online available from http:/www.hulldailym ail.co.uk

[24] Sewell P, Online available from http:/www.sewell-group.co.uk/news/sewell-360

[25] Mclaughlin N, Online available from http:/www.niallmclaug hlin.com

[26] K. Wilber, The Marriage of Sense and Soul, in The Collected Woks of Ken Wilber, Vol. 8, Smambhala Publications, Boston, 2000 